\title{
Prognostic nomogram for bladder cancer with brain metastases: a National Cancer Database analysis
}

Zhixian Yao ${ }^{1+} \mathbb{0}$, Zhong Zheng ${ }^{1 \dagger}$, Wu Ke ${ }^{1}$, Renjie Wang ${ }^{1}$, Xingyu Mu ${ }^{1}$, Feng Sun ${ }^{1}$, Xiang Wang ${ }^{1}$, Shivank Garg², Wenyin $\mathrm{Shi}^{2^{*}}$, Yinyan $\mathrm{He}^{3^{*}}$ and Zhihong Liu ${ }^{1^{*}}$

\begin{abstract}
Background: This study aimed to establish and validate a nomogram for predicting brain metastasis in patients with bladder cancer (BCa) and assess various treatment modalities using a primary cohort comprising 234 patients with clinicopathologically-confirmed BCa from 2004 to 2015 in the National Cancer Database.

Methods: Machine learning method and Cox model were used for nomogram construction. For BCa patients with brain metastasis, surgery of the primary site, chemotherapy, radiation therapy, palliative care, brain confinement of metastatic sites, and the Charlson/Deyo Score were predictive features identified for building the nomogram.

Results: For the original 169 patients considered in the model, the areas under the receiver operating characteristic curve (AUC) were $0.823(95 \% \mathrm{Cl} 0.758-0.889, \mathrm{P}<0.001)$ and 0.854 (95\% Cl 0.785-0.924, P<0.001) for 0.5- and 1-year overall survival respectively. In the validation cohort, the nomogram displayed similar AUCs of 0.838 ( $95 \% \mathrm{Cl} 0.738-$ $0.937, \mathrm{P}<0.001)$ and $0.809(95 \% \mathrm{Cl} 0.680-0.939, \mathrm{P}<0.001)$, respectively. The high and low risk groups had median survivals of 1.91 and 5.09 months for the training cohort and 1.68 and 8.05 months for the validation set, respectively (both $\mathrm{P}<0.0001$ ).
\end{abstract}

Conclusions: Our prognostic nomogram provides a useful tool for overall survival prediction as well as assessing the risk and optimal treatment for BCa patients with brain metastasis.

Keywords: Bladder cancer, Brain metastasis, Machine learning, Nomogram, Overall survival

\section{Background}

As the top ranked malignancy of the urinary system, bladder cancer $(\mathrm{BCa})$ incidence data in the US shows an estimated 79,030 (8th among all sites) new cases and 16,870 (8th among all sites) deaths in 2017 [1]. Unfortunately,

\footnotetext{
*Correspondence: wenyin.shi@jefferson.edu; amelie0228@126.com; drzhihongliu@sjtu.edu.cn

${ }^{\dagger}$ Zhixian Yao and Zhong Zheng contributed equally to this work

${ }^{1}$ Department of Urology, Shanghai General Hospital, Shanghai Jiao Tong

University School of Medicine, 100 Haining Road, Shanghai 200080,

People's Republic of China

${ }^{2}$ Department of Radiation Oncology, Sidney Kimmel Medical College at Thomas Jefferson University, Sidney Kimmel Cancer Center,

Philadelphia, PA, USA

${ }^{3}$ Department of Obstetrics and Gynecology, Shanghai General Hospital,

Shanghai Jiao Tong University School of Medicine, 100 Haining Road,

Shanghai 200080, People's Republic of China
}

$10-15 \%$ of BCa patients already have metastasis at initial diagnosis and 15-30\% high-grade $\mathrm{BCa}$ will eventually progress to advanced disease and lead to poor prognosis [2].

Despite an initial response to chemotherapy, patients with non-organ-confined disease fail to attain satisfactory survival [3]. Since no optimally effective chemotherapeutic modality has been found, patients with NOC disease can barely survive for more than 3-6 months [4]. According to a previous population-based study of the SEER database, only $4.1 \%(76 / 1862)$ BCa patients had brain metastases in a cohort of 1862 patients with metastatic sites [5]. Given the rarity of brain metastases at presentation, currently, there is no randomized phase II or III clinical trials exploring outcomes of this group. The survival prognosis of this subgroup calls for significant

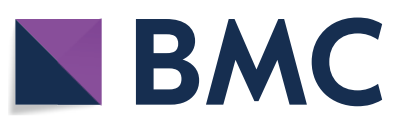

(c) The Author(s) 2019. This article is distributed under the terms of the Creative Commons Attribution 4.0 International License (http://creativecommons.org/licenses/by/4.0/), which permits unrestricted use, distribution, and reproduction in any medium, provided you give appropriate credit to the original author(s) and the source, provide a link to the Creative Commons license, and indicate if changes were made. The Creative Commons Public Domain Dedication waiver (http://creativecommons.org/ publicdomain/zero/1.0/) applies to the data made available in this article, unless otherwise stated. 
melioration when compared to those with cerebral metastasis from other malignancies [6].

Some reports have claimed that stereotactic radiosurgery and whole-brain irradiation can be a useful alternative approach for patients with brain metastasis in certain malignancies [7, 8]; however, suitable treatment for $\mathrm{BCa}$ patients with brain metastases remains unclear. A study conducted in 2002 in Cleveland retrospectively analyzed $16 \mathrm{BCa}$ patients with brain metastases and suggested more aggressive treatment rather than radiation therapy alone [9]. However, the cohort was too small to extract robust clinical traits. In 2010, Fokas et al. found no significant difference in survival after comparing radiotherapy alone with radiotherapy plus surgery in 62 patients with brain metastases from BCa [10]. Therefore, reconsideration of current medical strategies is indispensable, since the role of surgeries of the primary tumor or radiotherapy of brain lesions in the treatment of metastatic $\mathrm{BCa}$ is still obscure.

Although previous studies have identified several prognostic factors of poor outcome in advanced $\mathrm{BCa}$, such as the presence of visceral metastasis, anemia, and C-reactive protein (CRP) $[3,11,12]$, it remains unknown whether they could be applied to the clinical assessment. Currently, prognostic nomograms are widely applied as prognostic devices in oncologic medicine. With the ability to incorporate clinical characteristics to generate individual probabilities of clinical events, nomograms can aid clinical decisions and facilitate our drive towards personalized medicine [13]. The purpose of our study was to create a nomogram predicting overall survival (OS) of $\mathrm{BCa}$ patients with brain metastasis and evaluate suitable therapeutic modalities for this cohort.

\section{Materials and methods Study population}

The National Cancer Database (NCDB) was queried for patients initially diagnosed with histological confirmed BCa (topographical code C67, International Classification of Diseases for Oncology, 3rd edition) between 2004 and 2015. Patients with brain metastatic disease at the time of presentation were selected for the analysis.

Baseline medical traits (including age; sex, race; pathological grade; tumor histology, lymph node vascular invasion, and clinical stage [TNM] of the American Joint Committee on Cancer; surgical statuses of the primary and metastatic sites; chemotherapy; radiation therapy; and palliative care) were derived from medical records (Table 1). Other inclusion criteria were as follows: age $>18$ years; $\mathrm{BCa}$ as the primary cancer diagnosis; brain metastasis; other distant metastatic sites including bone, liver, lung, and distant lymph node involvement; active follow-up; and patients with $>30$ days of survival. Patients without sufficient information about distant metastatic sites or survival data were excluded. No detailed data were available regarding the specific types of chemotherapy or hormonal therapy or palliative care agents. Finally, we included 234 patients with the above-mentioned criteria. We used a computer-generated random seed to assign 169 of these patients to the training set, and 65 patients to the internal testing set for subsequent analysis. Work of flow is displayed in Fig. 1.

\section{Compliance with ethical standards}

The NCDB is a hospital-based registry of cases treated at American College of Surgeons Commission on Cancer accredited cancer programs. Extraction of data from the NCDB did not require extra informed consent. All the data were downloaded at the Sidney Kimmel Cancer Center of Thomas Jefferson University.

\section{Statistical analysis}

For feature selection, we used the least absolute shrinkage and selection operator (LASSO) method, which is a machine learning method suitable for the reduction of high-dimensional data [14]. Eighteen variables were used to select the most useful predictive features from the primary data set. The LASSO regression model analysis was performed using the glmnet package of $\mathrm{R}$ (R Foundation for Statistical Computing, Vienna, Austria).

Univariate and multivariate Cox regression analysis were performed to explore the independent prognostic factors via the survival package of $\mathrm{R}$. The Schoenfeld residuals method was applied to test the proportional hazards assumption for the Cox regression model fit. Each regression coefficient of selected variables was converted to a 0 to 100 scale proportion according to its contribution. These points were added across enrolled variables to generate total points, which were then transformed to predicted probabilities. For clinical use, the predictive performance of the nomogram was measured via time-dependent receiver operating characteristic (ROC) analysis with area under the curve (AUC) values. Calibration was employed with bootstrapping to decrease the bias of over-fitting. The $x$-axis represented the prediction calculated using the nomogram, and the $y$-axis the actual risk odds for the individual. The 45-degree line represented an ideal performance of the nomogram, in which the predicted outcome perfectly corresponded with the actual outcome. The model that incorporated the above independent predictors was developed and presented as the nomogram. Nomogram and calibration plots were obtained using the rms and nomogramEx packages of $R$.

Survival analysis was performed using the KaplanMeier method to probe the correlation between variables 
Table 1 Description of clinical characteristics and their values

\begin{tabular}{|c|c|c|}
\hline Clinical variables & Description & Values \\
\hline Age & Age of the patient at diagnosis & $<65$ years or $\geq 65$ years \\
\hline Sex & The gender of the patient & Male or female \\
\hline Race & The primary race of the person & White, black or others \\
\hline Grade & $\begin{array}{l}\text { Describes the tumor's resemblance to normal tissue (coded } \\
\text { according to ICD-O-3) }\end{array}$ & Well differentiated, poorly differentiated or Unknown \\
\hline Tumor_Stage & $\begin{array}{l}\text { NCDB analytic stage identifies the clinically or pathologically } \\
\text { determined size and/or extension of the primary tumor (CT) } \\
\text { as defined by the American Joint Committee on Cancer } \\
\text { (AJCC) }\end{array}$ & High (Stage III, IV) or low (Stage I, II) \\
\hline Lymph_nodes & $\begin{array}{l}\text { Identifies the clinically-determined absence or presence of } \\
\text { regional lymph node metastasis and describes the corre- } \\
\text { sponding extent as defined by the American Joint Commit- } \\
\text { tee on Cancer (AJCC) }\end{array}$ & Yes, no or unknown \\
\hline Histology & $\begin{array}{l}\text { Indicate the pathological histology of tumor cells (coded } \\
\text { according to ICD-O-3) }\end{array}$ & $\begin{array}{l}\text { Transitional cell carcinoma, papillary urothelial carcinoma, small } \\
\text { cell carcinoma or others }\end{array}$ \\
\hline Lymph_Vas_invasion & $\begin{array}{l}\text { Indicate the presence or absence of tumor cells in lymphatic } \\
\text { channels (other than lymph nodes) or blood vessels within } \\
\text { the primary tumor as noted microscopically by the patholo- } \\
\text { gist }\end{array}$ & Yes, no or unknown \\
\hline Met_Bone & $\begin{array}{l}\text { Indicate the presence of distant involvement of bone at the } \\
\text { time of diagnosis }\end{array}$ & Yes or no \\
\hline Met_Liver & $\begin{array}{l}\text { Indicate the presence of distant involvement of liver at the } \\
\text { time of diagnosis }\end{array}$ & Yes or no \\
\hline Met_Lung & $\begin{array}{l}\text { Indicate the presence of distant involvement of lung at the } \\
\text { time of diagnosis }\end{array}$ & Yes or no \\
\hline Surgery_Primary & $\begin{array}{l}\text { Records the surgical procedure and approach performed to } \\
\text { the primary site }\end{array}$ & $\begin{array}{l}\text { Minimal invasive surgery, non-minimal invasive surgery or no } \\
\text { surgery }\end{array}$ \\
\hline Chemotherapy & $\begin{array}{l}\text { Records of chemotherapy administrated as first course treat- } \\
\text { ment }\end{array}$ & Yes or no \\
\hline Radiation_Therapy & $\begin{array}{l}\text { Anatomic target volume is directed at tumors lying within the } \\
\text { substance of brain or its meninges }\end{array}$ & Yes or no \\
\hline Paliative_Care & Any care provided an effort to palliate or alleviate symptoms & Yes or no \\
\hline Brain_Confined_Met & $\begin{array}{l}\text { Indicate the presence of distant involvement of brain only or } \\
\text { brian combined with other organs at the time of diagnosis }\end{array}$ & Brain confined or non-brain confined \\
\hline CDCC_Score & $\begin{array}{l}\text { Charlson/Deyo Score, a weighted score derived from the } \\
\text { sum of the scores for each of the comorbid conditions } \\
\text { listed in the Charlson Comorbidity Score Mapping Table } \\
\text { (source http://dx.doi.org/10.17632/nn6y58v8vv.1\#file-a7273 } \\
\text { 5e9-15b5-4a10-aef5-deddad2463e8) }\end{array}$ & $0-3$ \\
\hline Surgery_Met & $\begin{array}{l}\text { Records the surgical removal of distant lymph nodes or other } \\
\text { tissues or organs beyond the primary site }\end{array}$ & Yes or no \\
\hline
\end{tabular}

and OS, and the log-rank test was performed to compare survival variance in different groups. Decision curve analysis were performed to compare with the current AJCC TNM staging system. All statistical tests and analyses were performed in R software version 3.5.1. Statistical significance was set at $<0.05$.

\section{Results}

\section{Clinicopathologic characteristics}

During the study procedure, 268 consecutive $\mathrm{BCa}$ patients with brain-involvement were identified from the NCDB. Of these, 234 patients with brain metastasis in accordance with the inclusion criteria were enrolled, and 169 and 65 patients were randomly divided into the training and internal validation cohorts, respectively. The clinicopathologic characteristics and baseline data in the primary and validation cohorts are provided in Table 2 . The median follow-up time was 3.38 (range: 1.08-61.21) months.

\section{Feature selection via LASSO}

LASSO with tenfold cross-validation generated 7 variables out of 18 features: Grade, Surgery_Primary, Chemotherapy, Radiation_Therapy, Paliative_Care, 


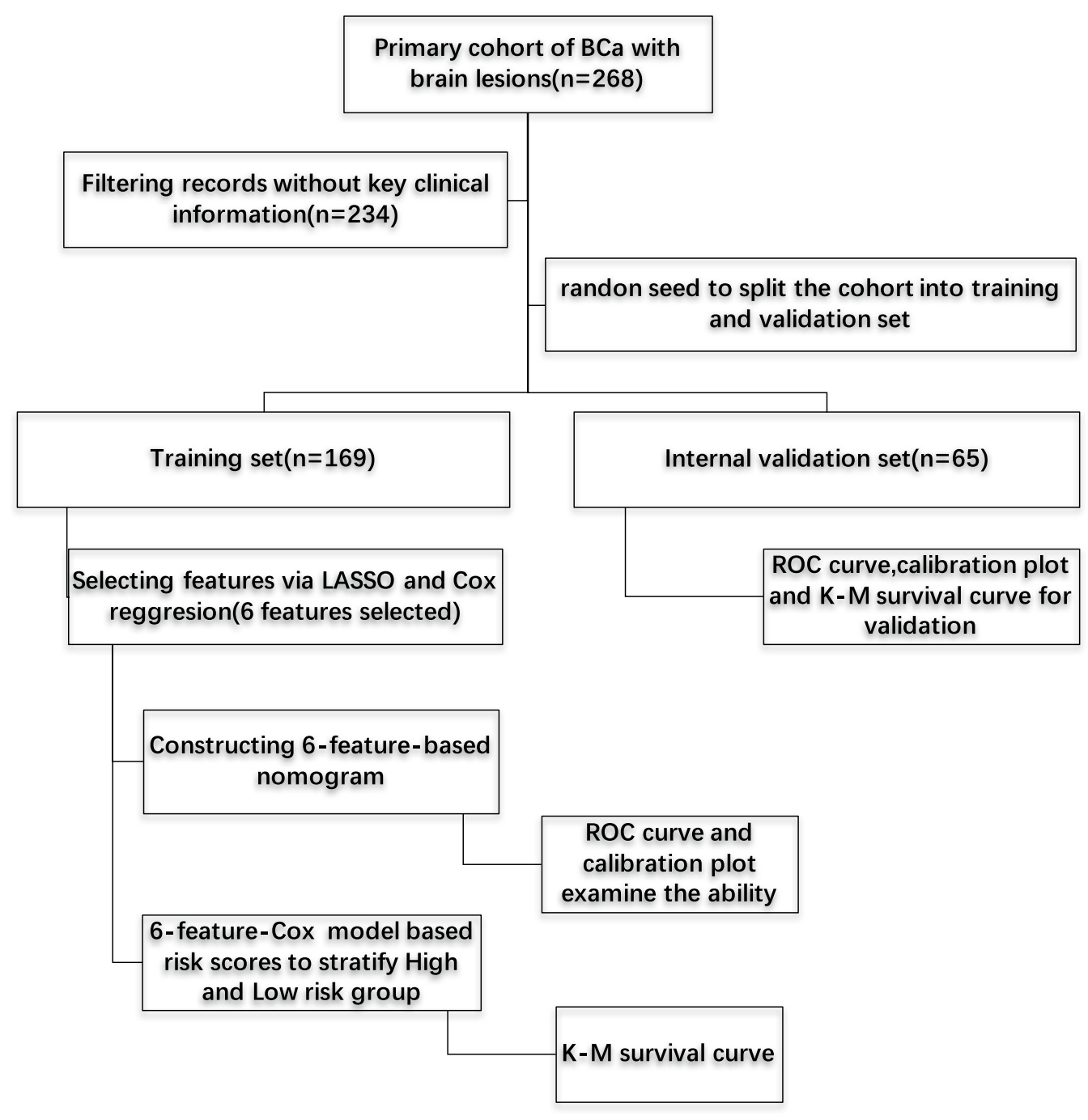

Fig. 1 Flowchart of the analysis

Brain_Confined_Met, and CDCC_Score (Fig. 2a, b). The results of the univariate and multivariate Cox regression of the primary cohort are recorded in Table 3. Surgery_Primary, Chemotherapy, Radiation_Therapy, Paliative_Care, Brain_Confined_Met, and CDCC_Score were chosen for further analysis (apart from Radiation_Therapy, all other variables were independent prognostic factors in the LASSO Cox model; the reason for including this variable will be explained in "Discussion") $P$ values for Schoenfeld residuals method were all $>0.05$ which fitted the proportional hazards assumption for the Cox model (Additional file 1: Fig. S1).

Development and validation of the prognostic nomogram The prognostic nomogram that integrated all selected factors for OS in the primary cohort is shown in Fig. 3. We then derived a formula to calculate the risk score for odds of death for every patient based on their individual status of the selected variables above. To take one patient for example (purple track in Fig. 3), basing on the selected features, the total points adds up to 323 and thus the corresponding 0.5- and 1-year death probabilities are 0.647 and 0.9 respectively. The equation of each variable and computational formula is presented in Table 4 . We further stratified those patients with an average or higher-than-average risk score into the high risk group and those with lower-than-average risk score into the low risk group (Table 1). In terms of 0.5- and 1-year OS of the training set, our six-clinical variable-based classifier demonstrated favorable discrimination with AUC values of 0.823 (95\% confidence interval [CI] 0.758-0.889, $\mathrm{P}<0.001$ ) and 0.854 (95\% CI 0.785-0.924, $\mathrm{P}<0.001$ ), respectively (Fig. 4a). The internal-bootstrapped calibration plot for the probability of survival at 0.5 or 1 year 
Table 2 Baseline characteristics and distribution of risk stratification of patients in the training and validation cohorts

\begin{tabular}{|c|c|c|c|c|c|c|}
\hline \multirow[t]{2}{*}{ Characteristics } & \multicolumn{3}{|l|}{ Training set (\%) } & \multicolumn{3}{|c|}{ Internal testing set (\%) } \\
\hline & Number of cases & High risk & Low risk & Number of cases & High risk & Low risk \\
\hline \multicolumn{7}{|l|}{ Age } \\
\hline$<65$ years & $71(42)$ & $32(18.9)$ & $39(23.1)$ & $22(33.8)$ & $11(16.9)$ & $11(16.9)$ \\
\hline$\geq 65$ years & $98(58)$ & $49(29)$ & $49(29)$ & $43(66.2)$ & $21(32.3)$ & $22(33.8)$ \\
\hline \multicolumn{7}{|l|}{ Sex } \\
\hline Male & $128(75.7)$ & $63(37.3)$ & $65(38.5)$ & $47(72.3)$ & $19(29.2)$ & $28(43.1)$ \\
\hline Female & $41(24.3)$ & $18(10.7)$ & $23(13.6)$ & $18(27.7)$ & $13(20)$ & $5(7.7)$ \\
\hline \multicolumn{7}{|l|}{ Race } \\
\hline White & $148(87.6)$ & $70(41.4)$ & $78(46.2)$ & $59(90.8)$ & $29(44.6)$ & $30(46.2)$ \\
\hline Black & $16(9.5)$ & $8(4.7)$ & $8(4.7)$ & $4(6.2)$ & $3(4.6)$ & $1(1.5)$ \\
\hline Others & $5(3)$ & $3(1.8)$ & $2(1.2)$ & $2(3.1)$ & $0(0)$ & $2(3.1)$ \\
\hline \multicolumn{7}{|l|}{ Grade } \\
\hline Well differentiated & $14(8.3)$ & $10(5.9)$ & $4(2.4)$ & $1(1.5)$ & $0(0)$ & $1(1.5)$ \\
\hline Poorly differentiated & $96(56.8)$ & $39(23.1)$ & $57(33.7)$ & $39(60)$ & 19 (29.2) & $20(30.8)$ \\
\hline Unknown & $59(34.9)$ & $32(18.9)$ & $27(16)$ & $25(38.5)$ & $13(20)$ & $12(18.5)$ \\
\hline \multicolumn{7}{|l|}{ Histology } \\
\hline TCC & $94(55.6)$ & $49(29)$ & $45(26.6)$ & $38(58.5)$ & $17(26.2)$ & $21(32.3)$ \\
\hline PUC & $42(24.9)$ & $15(8.9)$ & $27(16)$ & $8(12.3)$ & $5(7.7)$ & $3(4.6)$ \\
\hline SCC & $10(5.9)$ & $3(1.8)$ & $7(4.1)$ & $7(10.8)$ & $2(3.1)$ & $5(7.7)$ \\
\hline Others & $23(13.6)$ & $14(8.3)$ & $9(5.3)$ & $12(18.5)$ & $8(12.3)$ & $4(6.2)$ \\
\hline \multicolumn{7}{|l|}{ Tumor_Stage } \\
\hline Low & $13(7.7)$ & $7(4.1)$ & $6(3.6)$ & $4(6.2)$ & $2(3.1)$ & $2(3.1)$ \\
\hline High & $156(92.3)$ & $74(43.8)$ & $82(48.5)$ & $61(93.8)$ & $30(46.2)$ & $31(47.7)$ \\
\hline \multicolumn{7}{|l|}{ Lymph_nodes } \\
\hline No & 87 (51.5) & $39(23.1)$ & $48(28.4)$ & $33(50.8)$ & $16(24.6)$ & $17(26.2)$ \\
\hline Yes & $36(21.3)$ & $14(8.3)$ & $22(13)$ & $17(26.2)$ & $9(13.8)$ & $8(12.3)$ \\
\hline Unknown & $46(27.2)$ & $28(16.6)$ & $18(10.7)$ & $15(23.1)$ & $7(10.8)$ & $8(12.3)$ \\
\hline \multicolumn{7}{|l|}{ Lymph_Vas_Invasion } \\
\hline No & $31(18.3)$ & $12(7.1)$ & $19(11.2)$ & $12(18.5)$ & $5(7.7)$ & $7(10.8)$ \\
\hline Yes & $29(17.2)$ & $13(7.7)$ & $16(9.5)$ & $6(9.2)$ & $3(4.6)$ & $3(4.6)$ \\
\hline Unknown & $109(64.5)$ & $56(33.1)$ & $53(31.4)$ & $47(72.3)$ & $24(36.9)$ & $23(35.4)$ \\
\hline \multicolumn{7}{|l|}{ Met_Bone } \\
\hline No & $112(66.3)$ & $47(27.8)$ & $65(38.5)$ & $44(67.7)$ & $26(40)$ & $18(27.7)$ \\
\hline Yes & $57(33.7)$ & $34(20.1)$ & $23(13.6)$ & $21(32.3)$ & $6(9.2)$ & $15(23.1)$ \\
\hline \multicolumn{7}{|l|}{ Met_Liver } \\
\hline No & $129(76.3)$ & $61(36.1)$ & $68(40.2)$ & $50(76.9)$ & 25 (38.5) & $25(38.5)$ \\
\hline Yes & $40(23.7)$ & $20(11.8)$ & $20(11.8)$ & $15(23.1)$ & $7(10.8)$ & $8(12.3)$ \\
\hline \multicolumn{7}{|l|}{ Met_Lung } \\
\hline No & $100(59.2)$ & $40(23.7)$ & $60(35.5)$ & $34(52.3)$ & $16(24.6)$ & $18(27.7)$ \\
\hline Yes & $69(40.8)$ & $41(24.3)$ & $28(16.6)$ & $31(47.7)$ & $16(24.6)$ & $15(23.1)$ \\
\hline \multicolumn{7}{|l|}{ Surgery_Primary } \\
\hline Minimal invasive & $65(38.5)$ & $27(16)$ & $38(22.5)$ & $31(47.7)$ & $19(29.2)$ & $12(18.5)$ \\
\hline No & $83(49.1)$ & $48(28.4)$ & $35(20.7)$ & $29(44.6)$ & $9(13.8)$ & $20(30.8)$ \\
\hline Non-minimal invasive & $21(12.4)$ & $6(3.6)$ & $15(8.9)$ & $5(7.7)$ & $4(6.2)$ & $1(1.5)$ \\
\hline \multicolumn{7}{|l|}{ Chemotherapy } \\
\hline No & $97(57.4)$ & $77(45.6)$ & $20(11.8)$ & $36(55.4)$ & $28(43.1)$ & $8(12.3)$ \\
\hline Yes & $72(42.6)$ & $4(2.4)$ & $68(40.2)$ & $29(44.6)$ & $4(6.2)$ & $25(38.5)$ \\
\hline \multicolumn{7}{|l|}{ Radiation_Therapy } \\
\hline No & $89(52.7)$ & $50(29.6)$ & $39(23.1)$ & $38(58.5)$ & $14(21.5)$ & $24(36.9)$ \\
\hline
\end{tabular}


Table 2 (continued)

\begin{tabular}{|c|c|c|c|c|c|c|}
\hline \multirow[t]{2}{*}{ Characteristics } & \multicolumn{3}{|l|}{ Training set (\%) } & \multicolumn{3}{|c|}{ Internal testing set (\%) } \\
\hline & Number of cases & High risk & Low risk & Number of cases & High risk & Low risk \\
\hline Yes & $80(47.3)$ & $31(18.3)$ & $49(29)$ & $27(41.5)$ & $18(27.7)$ & $9(13.8)$ \\
\hline \multicolumn{7}{|l|}{ Palliative_Care } \\
\hline No & $122(72.2)$ & $62(36.7)$ & $60(35.5)$ & $47(72.3)$ & $21(32.3)$ & $26(40)$ \\
\hline Yes & $47(27.8)$ & $19(11.2)$ & $28(16.6)$ & $18(27.7)$ & $11(16.9)$ & $7(10.8)$ \\
\hline \multicolumn{7}{|c|}{ Brain_Confined_Met } \\
\hline No & $67(39.6)$ & $24(14.2)$ & $43(25.4)$ & $22(33.8)$ & $13(20)$ & $9(13.8)$ \\
\hline Yes & $102(60.4)$ & $57(33.7)$ & 45 (26.6) & $43(66.2)$ & $19(29.2)$ & $24(36.9)$ \\
\hline \multicolumn{7}{|l|}{ CDCC_Score } \\
\hline 0 & $116(68.6)$ & $50(29.6)$ & $66(39.1)$ & $46(70.8)$ & $23(35.4)$ & $23(35.4)$ \\
\hline 1 & $37(21.9)$ & $19(11.2)$ & $18(10.7)$ & $12(18.5)$ & $8(12.3)$ & $4(6.2)$ \\
\hline 2 & $10(5.9)$ & $7(4.1)$ & $3(1.8)$ & $5(7.7)$ & $1(1.5)$ & $4(6.2)$ \\
\hline 3 & $6(3.6)$ & $5(3)$ & $1(0.6)$ & $2(3.1)$ & $0(0)$ & $2(3.1)$ \\
\hline \multicolumn{7}{|l|}{ Surgery_Met } \\
\hline No & $144(85.2)$ & $72(42.6)$ & $72(42.6)$ & $55(84.6)$ & 25 (38.5) & $30(46.2)$ \\
\hline Yes & 25 (14.8) & $9(5.3)$ & $16(9.5)$ & $10(15.4)$ & $7(10.8)$ & $3(4.6)$ \\
\hline
\end{tabular}

TCC transitional cell carcinoma, PUC papillary urothelial carcinoma, SCC small cell carcinoma
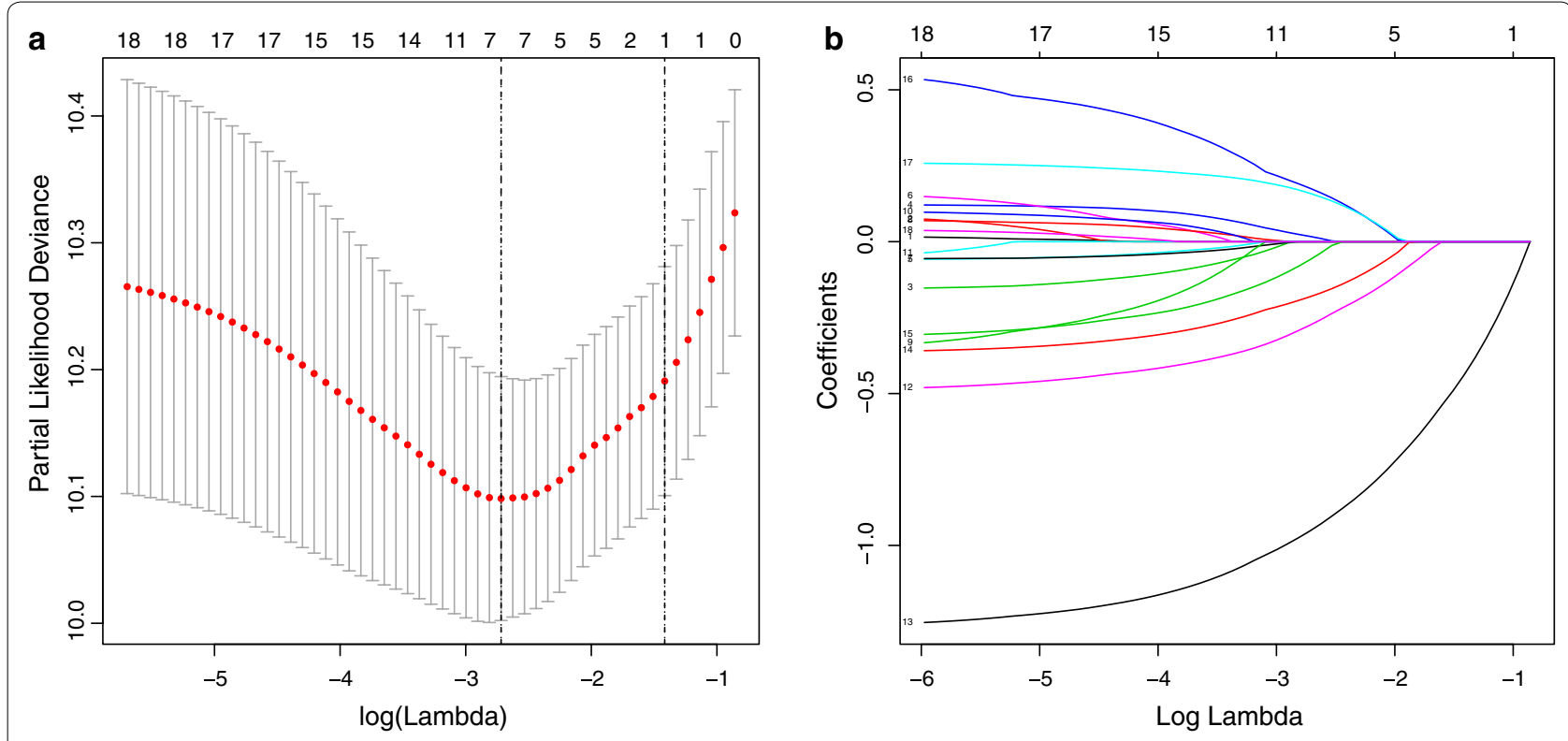

Fig. 2 Clinical trait selection via the least absolute shrinkage and selection operator (LASSO) cox regression model. a Tenfold cross-validated error (first vertical line equals the minimum error (lambda $=0.066$ ), whereas the second vertical line shows the cross-validated error within 1 standard error of the minimum). $\mathbf{b}$ The profile of coefficients in the model at varying levels of penalization plotted against the log (lambda) sequence

after surgery showed an optimal agreement between prediction by nomogram and actual observation (Fig. 4b, c). In the validation cohort, the nomogram displayed similar AUC values of $0.838(95 \%$ CI $0.738-0.937, \mathrm{P}<0.001)$ and 0.809 (95\% CI $0.680-0.939, \mathrm{P}<0.001$ ) for the estimation of survival (Fig. 4d). There was also a well-behaved calibration curve for the survival estimation (Fig. 4e, f).
Kaplan-Meier survival analysis yielded a significant difference in survival between the training cohort and validation set. The median survival of the High and Low risk groups were 1.91 and 5.09 months in the training cohort (Fig. 5a) and 1.68 and 8.05 months in the validation set (Fig. 5b), respectively (both $\mathrm{P}<0.0001$ ). 
Table 3 Univariate and multivariate Cox regression analysis of BCa patients based on clinicopathological characteristics derived from NCDB data in the training cohort

\begin{tabular}{|c|c|c|c|c|}
\hline Characteristics & $\begin{array}{l}\text { Univariate analysis HR } \\
(95 \% \mathrm{Cl})\end{array}$ & P value & $\begin{array}{l}\text { Multivariate analysis HR } \\
(95 \% \mathrm{Cl})\end{array}$ & $P$ value \\
\hline Age ( $<65$ years vs. $\geq 65$ years $)$ & $1.117(0.819-1.525)$ & 0.48 & $1.032(0.705-1.511)$ & 0.87 \\
\hline Sex (male vs. female) & $0.861(0.602-1.233)$ & 0.42 & $1.166(0.756-1.797)$ & 0.49 \\
\hline \multicolumn{5}{|l|}{ Race } \\
\hline White vs. black & $0.871(0.509-1.489)$ & 0.61 & $0.956(0.523-1.747)$ & 0.88 \\
\hline White vs. others & $0.889(0.363-2.174)$ & 0.80 & $0.524(0.197-1.39)$ & 0.19 \\
\hline \multicolumn{5}{|l|}{ Grade } \\
\hline Well differentiated vs. poorly differentiated & $0.896(0.511-1.574)$ & 0.70 & $1.317(0.653-2.656)$ & 0.44 \\
\hline Well differentiated vs. unknown & $1.144(0.636-2.057)$ & 0.65 & $1.634(0.753-3.546)$ & 0.21 \\
\hline \multicolumn{5}{|l|}{ Histology } \\
\hline TCC vs. PUC & $0.851(0.588-1.232)$ & 0.39 & $1.181(0.738-1.89)$ & 0.49 \\
\hline TCC vs. SCC & $1.083(0.563-2.087)$ & 0.81 & $1.495(0.714-3.13)$ & 0.29 \\
\hline TCC vs. others & $0.916(0.578-1.45)$ & 0.71 & $0.629(0.363-1.09)$ & 0.10 \\
\hline \multicolumn{5}{|l|}{ Lymph_nodes } \\
\hline No vs. yes & $0.835(0.564-1.234)$ & 0.37 & $0.808(0.51-1.28)$ & 0.36 \\
\hline No vs. unknown & $0.985(0.682-1.422)$ & 0.93 & $0.761(0.485-1.196)$ & 0.24 \\
\hline \multicolumn{5}{|l|}{ Lymph_Vas_Invasion } \\
\hline No vs. yes & $1.098(0.658-1.832)$ & 0.72 & $1.494(0.816-2.736)$ & 0.19 \\
\hline No vs. unknown & $1.291(0.859-1.94)$ & 0.22 & $1.269(0.764-2.107)$ & 0.36 \\
\hline Tumor_Stage (low vs. high) & $1.247(0.704-2.21)$ & 0.45 & $1.089(0.536-2.211)$ & 0.81 \\
\hline Met_Bone (no vs. yes) & $1.026(0.742-1.42)$ & 0.88 & $0.61(0.374-0.997)$ & 0.05 \\
\hline Met_Liver (no vs. yes) & $0.978(0.683-1.4)$ & 0.90 & $1.223(0.761-1.966)$ & 0.41 \\
\hline Met_Lung (no vs. yes) & $1.317(0.962-1.802)$ & 0.09 & $0.878(0.525-1.469)$ & 0.62 \\
\hline \multicolumn{5}{|l|}{ Surgery primary } \\
\hline Minimal invasive surgery vs. no surgery & $1.44(1.031-2.011)$ & 0.03 & $2.529(1.609-3.975)$ & $<0.001$ \\
\hline Minimal invasive surgery vs. non-minimal invasive & $0.923(0.558-1.525)$ & 0.75 & $1.253(0.672-2.334)$ & 0.48 \\
\hline Chemotherapy (no vs. yes) & $0.353(0.25-0.498)$ & $<0.001$ & $0.213(0.137-0.332)$ & $<0.001$ \\
\hline Radiation_Therapy (no vs. yes) & $0.723(0.53-0.986)$ & 0.04 & $0.708(0.486-1.031)$ & 0.07 \\
\hline Palliative_Care (no vs. yes) & $0.922(0.651-1.305)$ & 0.65 & $0.631(0.413-0.964)$ & 0.03 \\
\hline Brain_Confined_Met (non-brain confined vs. brain confined) & $1.248(0.911-1.71)$ & 0.17 & $2.229(1.144-4.345)$ & 0.02 \\
\hline \multicolumn{5}{|l|}{ CDCC_Score } \\
\hline 0 vs. 1 & $1.29(0.886-1.878)$ & 0.18 & $1.439(0.929-2.23)$ & 0.10 \\
\hline 0 vs. 2 & $1.529(0.798-2.926)$ & 0.20 & $1.865(0.861-4.038)$ & 0.11 \\
\hline 0 vs. 3 & $2.14(0.932-4.91)$ & 0.07 & $2.545(1.035-6.256)$ & 0.04 \\
\hline Surgery_Met (yes vs. no) & $0.9(0.58-1.396)$ & 0.64 & $0.918(0.546-1.542)$ & 0.75 \\
\hline
\end{tabular}

Moreover, the decision curve analysis demonstrated that when the threshold probability was greater than 0.4 , the nomogram presented more net benefit than TNM system in terms of OS prediction (Fig. 6).

\section{Discussion}

In this study, we developed and validated a novel prognostic tool based on six clinical variables to improve the prediction of OS for patients with confirmed $\mathrm{BCa}$ with metastatic brain lesions. Our results showed that this tool can well categorize patients into high-risk and lowrisk groups with large differences in OS.
Generally, in our research, prognostic factors are closely related to the choices of treatment modalities, as well as the comorbidities and metastatic conditions of the patient. Known as the best method of determining comorbidity conditions, higher Charlson/Deyo Score (CDCC_Score) is reported as a poor prognostic factor for overall mortality and cancer-specific mortality in metastatic BCa [15], consistent with our findings. In a previous study, multisite metastasis was found to be able to independently predict worse OS compared with single metastatic sites in $\mathrm{BCa}$ patients [5]. Our results are in line 


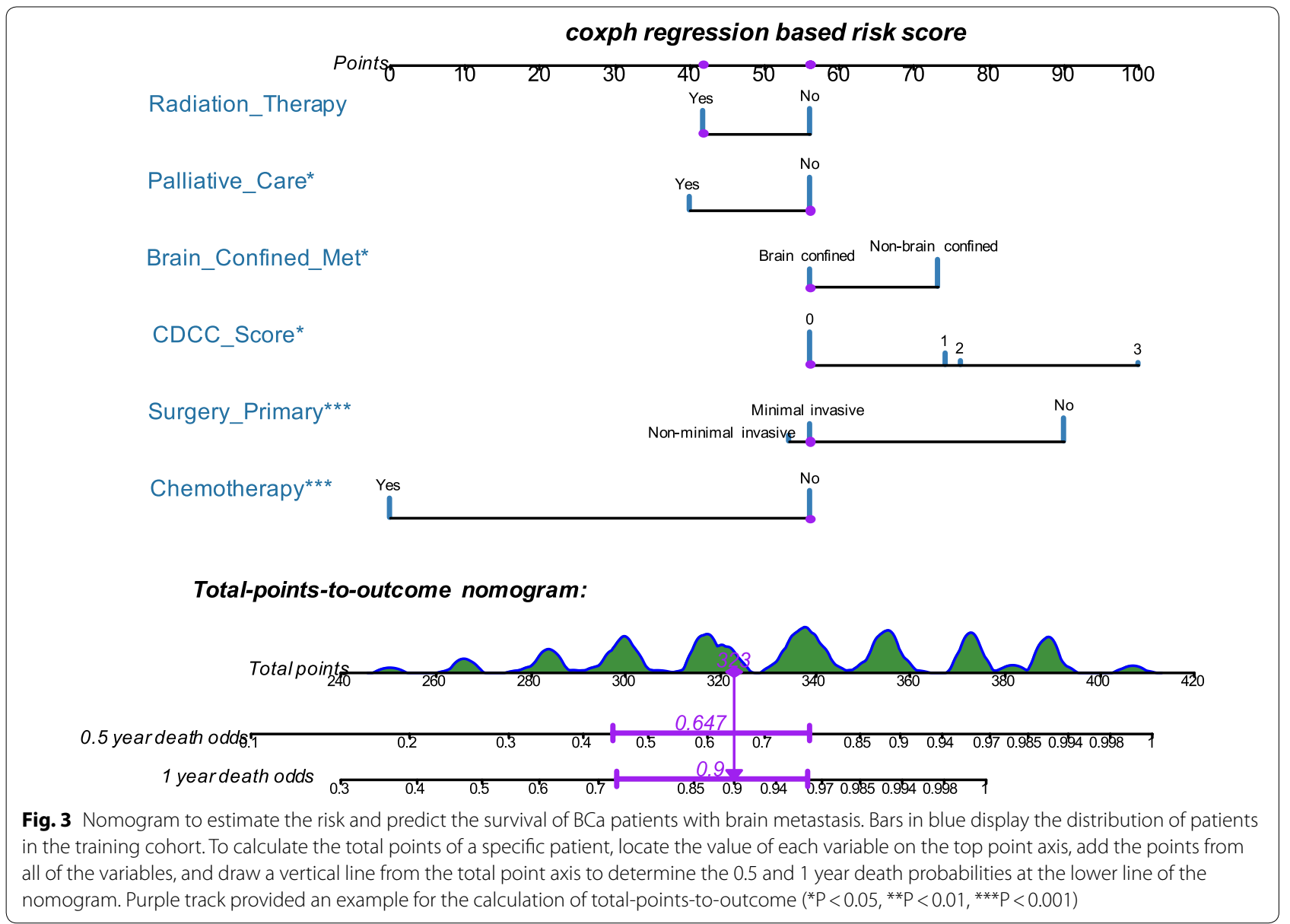

Table 4 The risk point of each variable and computational formula of OS

\begin{tabular}{|c|c|c|}
\hline Clinical variables & Values & Risk points \\
\hline \multirow[t]{2}{*}{ Radiation_Therapy } & No & 56 \\
\hline & Yes & 42 \\
\hline \multirow[t]{2}{*}{ Palliative_Care } & No & 56 \\
\hline & Yes & 40 \\
\hline \multirow[t]{2}{*}{ Brain_Confined_Met } & Non-brain confined & 73 \\
\hline & Brain confined & 56 \\
\hline \multirow[t]{4}{*}{ CDCC_Score } & 1 & 56 \\
\hline & 2 & 74 \\
\hline & 3 & 76 \\
\hline & 4 & 100 \\
\hline \multirow[t]{3}{*}{ Surgery_Primary } & No & 90 \\
\hline & Minimal invasive & 56 \\
\hline & Non-minimal invasive & 53 \\
\hline \multirow[t]{2}{*}{ Chemotherapy } & No & 56 \\
\hline & Yes & 0 \\
\hline
\end{tabular}

0.5 -Year Survival $=7.5 e-08 *$ points $\wedge 3-2.7837 \mathrm{e}-05 *$ points

$\wedge 2-0.001082565 *$ points +0.815518912

1 -Year survival $=1.21 \mathrm{e}-07 *$ points $\wedge 3-2.3544 \mathrm{e}-05 *$ points

$\wedge 2-0.003130703 *$ points +0.651899934 with the study above since brain-confined metastatic disease was related with better survival.

Treatment for the metastatic group is not beyond dispute. Our study included 4 treatment variables: Surgery Primary, Surgery_Met, Chemotherapy, Paliative_Care and Radiation_Therapy.

A previous study indicated that surgical management of the primary $\mathrm{BCa}$ might contribute to long-term disease-free survival in selected patients [16]. Chen et al. also suggested that surgical management of the primary BCa might improve OS outcomes among patients [17]. Our study uncovered that brain metastatic BCa patients can still benefit from surgical operation of the primary site via minimal invasive surgery or otherwise. As for surgeries of the metastatic site, limited conclusions could be drawn for the lack of unanimous reporting elements and resection of solitary lung metastasis may result in OS improvement when integrated with chemotherapy [18]. As shown in the nomogram, though resistance may easily show up, chemotherapy still exerts maximal survival benefit for brain-metastatic BCa patients, which correlates to the first-line treatment of the European Association 

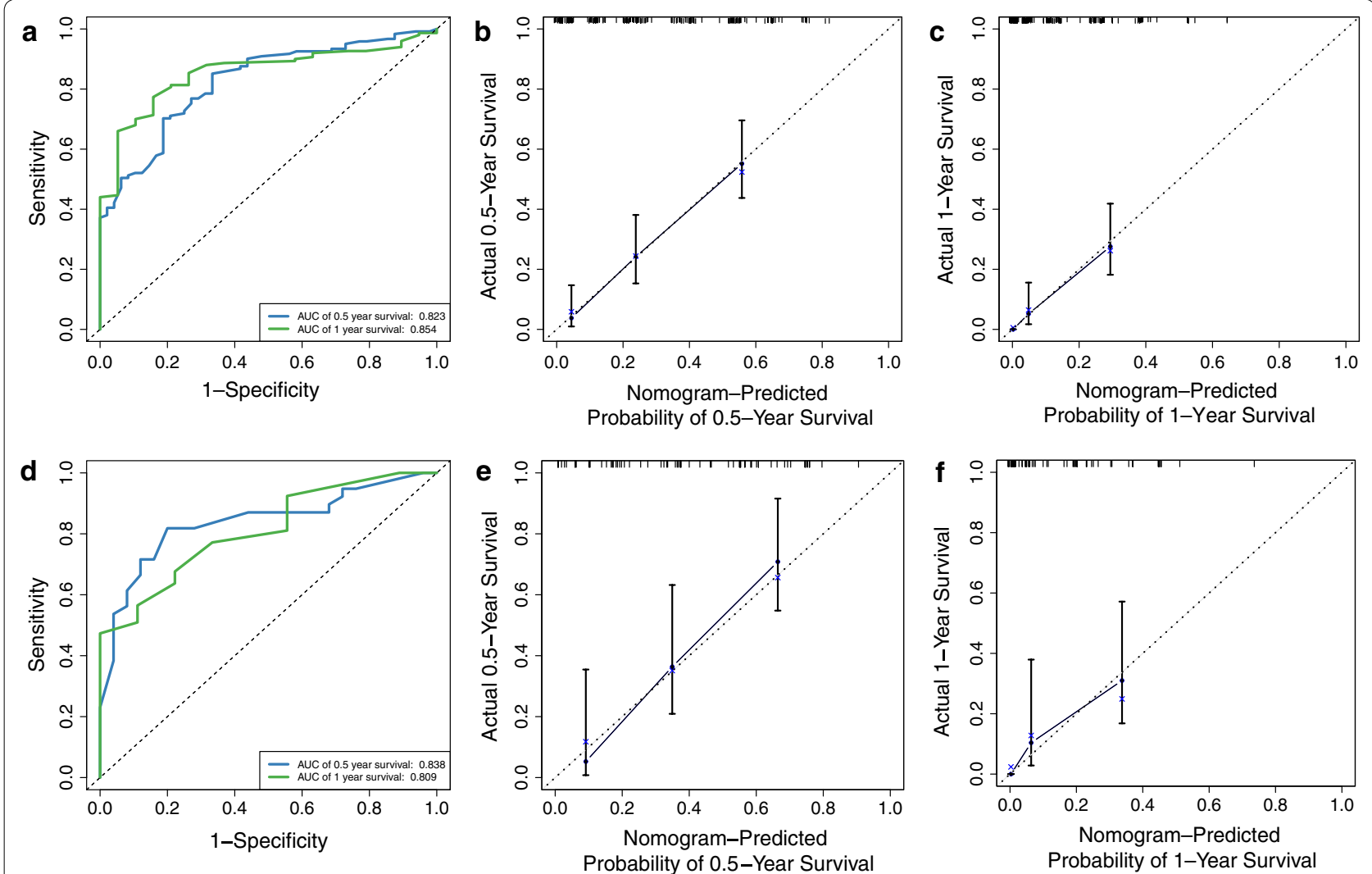

Fig. 4 Time-dependent ROC curves comparing the prognostic accuracy of nomogram in BCa patients with metastatic brain lesions in the training cohort (a) and validation set (d). Validity of the predictive performance of the nomogram in the training cohort (b, $\mathbf{c})$ and validation set (e, f). Nomogram-predicted probability of overall survival is plotted on the $x$-axis; actual overall survival is plotted on the $y$-axis. $R O C$ receiver operator characteristic, $A \cup C$ area under the curve

of Urology guidelines [19]. Given that more than half of patients with metastatic urothelial cancer are unfit for cisplatin-based chemotherapy, the choice of chemotherapy combination will have to depend on the health condition of patients. Consensus from an international survey among urologic experts was reached to define patients unfit for cisplatin-based chemotherapy, which was as follows: performance score $>1$, glomerular filtration rate $\leq 60 \mathrm{ml} / \mathrm{min} / 1.73 \mathrm{~m}^{2}$, grade 2 audiometric loss and peripheral neuropathy, and New York Heart Association class III heart failure [20, 21]. Palliative care is defined as any procedures to alleviate symptoms distinguishable from the same modality used for curative intent, which may include surgery, radiation therapy, systemic therapy, and/or other pain management drugs. Advanced $\mathrm{BCa}$ can be associated with problems like ureteral obstruction, persistent bleeding, pain, and/or voiding complaints; palliative care may prolong life expectancy in these patients [22]. The variable Radiation_Therapy was fitted into the analysis because although the P value 0.07 slightly surpassed 0.05 in the multivariate Cox model, it was 0.04 in the univariate analysis. Moreover, for brain metastatic cancer, conventional fractionated whole brain radiotherapy is still frequently used as a standard therapy [23]; thus, we included it in the prognostic nomogram for clinical consideration.

To the best of our knowledge, this is the largest cohort study exploring the prognostic significance of $\mathrm{BCa}$ with brain metastasis and the effect of various treatments on patients' prognoses; however, several limitations are still noteworthy. For example, information regarding metastasectomy for specific metastatic sites was incomplete. In addition, there was a lack of details and sequences concerning chemotherapy, endocrine therapy, immunological treatment, and radiation therapy. As a retrospective study population from different medical facilities, some baseline characteristics may be non-uniform and external validation cohorts are needed to confirm the predictive accuracy of the nomogram. 


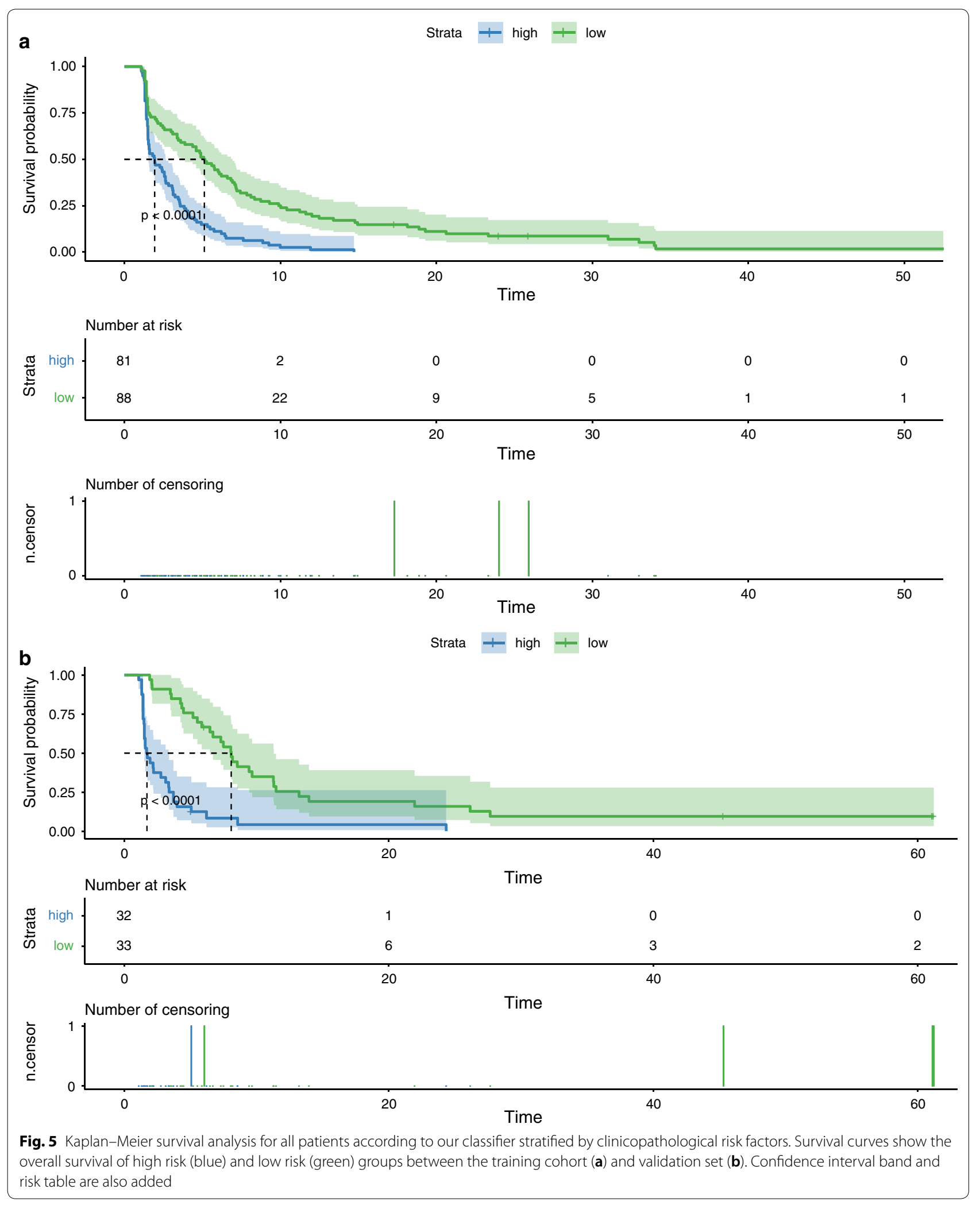




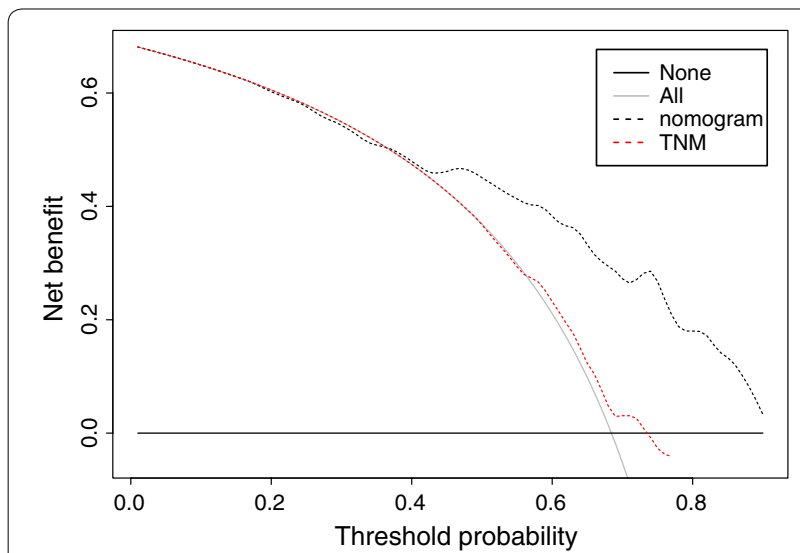

Fig. 6 Decision curve analysis for OS. Black line: all victims dead. Gray line: none victims dead. Black dashed line: model of the nomogram. Red dashed line: staging system of TNM

\section{Conclusion}

By combining six clinical factors of brain-metastatic $\mathrm{BCa}$ patients, we constructed a prognostic nomogram. The model provides an optimal estimation of OS and reference for suitable treatments in $\mathrm{BCa}$ patients with brain metastasis.

\section{Supplementary information}

Supplementary information accompanies this paper at https://doi. org/10.1186/s12967-019-2109-7.

Additional file 1: Fig. S1. The graphical verification of proportional hazards assumption for the Cox regression model.

\section{Abbreviations}

BCa: bladder cancer; AUC: area under the receiver operating characteristic curve; CRP: C-reactive protein; OS: overall survival; NCDB: National Cancer Database; LASSO: least absolute shrinkage and selection operator; Cl: confidence interval; CDCC_Score: Charlson/Deyo Score.

\section{Acknowledgements}

Not applicable.

\section{Authors' contributions}

$Z X Y$ and $Z Z$ contributed equally to the formation this manuscript. ZHL, YYH and WYS designed and supervised the procedure. SG, ZXY and ZZ collected and analyzed the data. KW and ZXY visualized the result. RJW and XYM provided the statistical guidance. FS and XW polished the manuscript. All authors read and approved the final manuscript.

\section{Funding}

This work was supported by the National Natural Science Foundation of China (81672515), Shanghai Pujiang Program (16PJD039) and Shanghai Municipal Education Commission—Gaofeng Clinical Medicine Grant (20172019).

\section{Availability of data and materials}

Original data for BCa patients with brain metastasis can be found at http:// dx.doi.org/10.17632/nn6y58v8vv.1\#file-a72735e9-15b5-4a10-aef5-dedda d2463e8.
Ethics approval and consent to participate

Extraction of data from the NCDB did not require extra informed consent.

\section{Consent for publication}

Not applicable.

\section{Competing interests}

The authors declare that they have no competing interests.

Received: 22 April 2019 Accepted: 26 October 2019

Published online: 09 December 2019

\section{References}

1. Siegel RL, Miller KD, Jemal A. Cancer statistics, 2017. CA Cancer J Clin. 2017;67:7-30.

2. Stein JP, et al. Radical cystectomy in the treatment of invasive bladder cancer: long-term results in 1,054 patients. J Clin Oncol Off J Am Soc Clin Oncol. 2001;19:666-75.

3. von der Maase $\mathrm{H}$, et al. Long-term survival results of a randomized trial comparing gemcitabine plus cisplatin, with methotrexate, vinblastine, doxorubicin, plus cisplatin in patients with bladder cancer. J Clin Oncol Off J Am Soc Clin Oncol. 2005:23:4602-8.

4. Sternberg CN, Vogelzang NJ. Gemcitabine, paclitaxel, pemetrexed and other newer agents in urothelial and kidney cancers. Crit Rev Oncol Hematol. 2003;46(Suppl):S105-15.

5. Dong F, et al. Prognostic value of site-specific metastases and therapeutic roles of surgery for patients with metastatic bladder cancer: a populationbased study. Cancer Manag Res. 2017;9:611-26.

6. Tsao MN, et al. Radiotherapeutic and surgical management for newly diagnosed brain metastasis(es): an American Society for Radiation Oncology evidence-based guideline. Pract Radiat Oncol. 2012;2:210-25.

7. Rades D, et al. Comparison of stereotactic radiosurgery (SRS) alone and whole brain radiotherapy (WBRT) plus a stereotactic boost (WBRT + SRS) for one to three brain metastases. Strahlenther Onkol Organ Dtsch Rontgengesellschaft Al. 2008;184:655-62.

8. Brown PD, et al. Effect of radiosurgery alone vs radiosurgery with whole brain radiation therapy on cognitive function in patients with 1 to 3 brain metastases: a randomized clinical trial. JAMA. 2016;316:401-9.

9. Mahmoud-Ahmed AS, et al. Brain metastases from bladder carcinoma: presentation, treatment and survival. J Urol. 2002;167:2419-22.

10. Fokas E, Henzel M, Engenhart-Cabillic R. A comparison of radiotherapy with radiotherapy plus surgery for brain metastases from urinary bladder cancer: analysis of 62 patients. Strahlenther Onkol Organ Dtsch Rontgengesellschaft Al. 2010;186:565-71.

11. Bellmunt J, et al. Prognostic factors in patients with advanced transitional cell carcinoma of the urothelial tract experiencing treatment failure with platinum-containing regimens. J Clin Oncol Off J Am Soc Clin Oncol. 2010;28:1850-5.

12. Ishioka J, et al. Development of a nomogram incorporating serum C-reactive protein level to predict overall survival of patients with advanced urothelial carcinoma and its evaluation by decision curve analysis. $\mathrm{Br} J$ Cancer. 2012;107:1031-6.

13. Balachandran VP, Gonen M, Smith JJ, DeMatteo RP. Nomograms in oncology: more than meets the eye. Lancet Oncol. 2015;16:e173-80.

14. Tibshirani R. Regression shrinkage and selection via the Lasso. J R Stat Soc Ser B Methodol. 1996;58:267-88.

15. Mayr R, et al. Predictive capacity of four comorbidity indices estimating perioperative mortality after radical cystectomy for urothelial carcinoma of the bladder. BJU Int. 2012;110:E222-7.

16. Herr HW, Donat SM, Bajorin DF. Post-chemotherapy surgery in patients with unresectable or regionally metastatic bladder cancer. J Urol. 2001;165:811-4.

17. Chen C, Hu L, Chen Y, Hou J. The prognostic value of histological subtype in patients with metastatic bladder cancer. Oncotarget. 2017;8:28408-17.

18. Nakagawa T, et al. Oncologic outcome of metastasectomy for urothelial carcinoma: who is the best candidate? Ann Surg Oncol. 2017;24:2794-800. 
19. Alfred Witjes J, et al. Updated 2016 EAU guidelines on muscle-invasive and metastatic bladder cancer. Eur Urol. 2017;71:462-75.

20. Hussain SA, et al. A study of split-dose cisplatin-based neo-adjuvant chemotherapy in muscle-invasive bladder cancer. Oncol Lett. 2012;3:855-9.

21. Morales-Barrera R, et al. Cisplatin and gemcitabine administered every two weeks in patients with locally advanced or metastatic urothelial carcinoma and impaired renal function. Eur J Cancer Oxf Engl. 2012:1990(48):1816-21.

22. Ghahestani SM, Shakhssalim N. Palliative treatment of intractable hematuria in context of advanced bladder cancer: a systematic review. Urol J. 2009;6:149-56.
23. Tsao MN, et al. International practice survey on the management of brain metastases: third international consensus workshop on palliative radiotherapy and symptom control. Clin Oncol. 2012;24:e81-92.

\section{Publisher's Note}

Springer Nature remains neutral with regard to jurisdictional claims in published maps and institutional affiliations.
Ready to submit your research? Choose BMC and benefit from:

- fast, convenient online submission

- thorough peer review by experienced researchers in your field

- rapid publication on acceptance

- support for research data, including large and complex data types

- gold Open Access which fosters wider collaboration and increased citations

- maximum visibility for your research: over $100 \mathrm{M}$ website views per year

At BMC, research is always in progress.

Learn more biomedcentral.com/submissions 